\title{
Employment and Income Potentiality of Tourism Development in Amhara Region Ethiopia. \\ *Ajala 0.A.
}

\begin{abstract}
A few members of less developed countries of sub-Sahara Africa have realized the potential of tourism development for rapid socio-economic development, capable of generating foreign exchange; reduce unemployment and improving the standard of the people. Amhara region of Ethiopia is an example of regions blessed with abundance and diversified tourism sites with potentials of contributing to the socio-economic development not only of the region but also to the country at large. This paper examines four Tourism Enterprises which include Hotel, Souvenir, Tour guide and Water transport businesses to pin point the potentiality of tourism as catalyst of development. Data were collected from both primary and secondary sources, using inventory field survey and questionnaire administration. Data generated were analysed using simple statistical methods as frequencies and percentages. It concludes that developments of Tourism Businesses are generators of employment and income not only for the entrepreneurs but to the entire region with a high multiplier effect on the national economy.
\end{abstract}

Key Words: Tourism Enterprises, Employment, Income, Amhara Region and Ethiopia.

\section{Introduction}

Tourism has become an appealing development strategy for the Less Developed Countries in dire need of alternative source of foreign exchange earnings. Next to oil, tourism is the net foreign exchange earner at the international level. It is the highest employer of labour in the tertiary sector of the World economy and the second largest after agriculture. Tourism potential impact on the economy cut across several sectors to includetransportation, manufacturing, food processing and packaging, construction, trade and commerce and other ancillary services. It is an international commodity, thus it has a global market from where it draws its patronage and there is no age barrier for its customers.

However, the full potential of tourism as a development option has yet to be realized in many of the developing countries that have embraced the concept. Also there is a dearth of researches focusing on the analysis of the regional impact of tourism in the Sub-Saharan African Countries. Such researches could spur policy shift towards tourism so as to realize the full potential of its adoption as a development strategy.

This paper is an attempt to fill this gap particularly in Africa, using Amhara region of Ethiopia as a case to unearth the employment and income potentiality of tourism development not only for the study area but also for other African countries, where tourism industry is at its crawling stage.

\section{Tourism in the Development Paradigm}

Regional development strategies in the developing countries of Sub-Saharan Africa have witnessed several changes since the second half of the last century. The success and failure of different strategies adopted by these countries has been at varying degrees and dimensions from one country to the other.

Some of these strategies had focused on industrialization, exploration of mineral resources, and exportation of primary products and concentration of investments in the major urban centres at the expense of the regions. The basic theory underpinning these types of development strategies is the "Growth pole theory" developed by Perroux (1950) which was modified by the works of Myrdal (1957), Hirschmann (1958) and Bouldeville (1966) as "Growth Centre Theory". The inability of the growth centre models to bring about the desired equitable balanced development and the increasing disparity in the level of development helped to fuel the search for alternative paradigm for development since the past three decades.

According to World Bank (1975), regional development is a process of growth, transformation and progress. The growth is manifest able in retaining and absorbing youthful progressive and productive population. It also implies restructuring of economy in order to satisfy the material needs and aspiration of the people, particularly the rural masses that constitutes a larger proportion of the population. It must, in addition, promote individual and collective 
incentives to participate in the process of development. The "progress" content of regional development is the transformation of the monotonous and stagnating condition of people in the countryside to a dynamic and exciting one.

Development is dependent on the level of natural resource endowment and level of technology of a nation among others (Darwent, 1975). One often neglected but promising resource for development in most Less Developed Countries (LDCs) is the tourism resources. In recent time regional development strategy has now focused on tourism in the dynamics of development strategy. Many less developed Countries have realized tourism resources in their country as endowment with potential of rapid socioeconomic development, capable of generating foreign exchange, reducing unemployment and improving the standard of living of the people (Ajala, 2007).

Tourism is a "propulsive industry" as opined by the proponents of "Growth pole theory"- which is characterized by a large size, a high innovative ability and relatively rapid growth. Tourism is capable of transmitting growth and change and at the same time. It attracts forces needed to sustain further growth and change with large matrix of multiplier effects. It is an international commodity, thus it has a global market from where it draws its patronage and there is no age barrier for its customers (Ajala, 2007).

Tourism is defined as leisure industry; "which operates within capabilities for regeneration and future productivity of natural resources; recognizes the contribution of people and communities, costumes and lifestyles to the tourism experience; accept that these people must have equitable share in the economic benefits of tourism and guided by the wishes of the local people and communities in the host area" (WTTO and IHRA, 1999). Tourism environment therefore comprises of physical and human components. The physical component includes- landscape scenery, weather and climate, water and natural biodiversity of plants and animals; while the human component encompasses history, culture and tradition of the people, all these provide challenges and adventures for people.

Tourism Enterprises are defined in the context of this paper as business units which provide direct services to tourist in a given tourist destination. This includes such services as hotel services, souvenir shops, tour guide, special transport services ( such as boat, horse riding, cycling, cable cart etc.).

In the context of development paradigm, tourism is a propulsive industry or a lead firm capable of generating both "spread/trickledown" and "backwash/ polarization" effect (Myrdal, 1975; Hirschman, 1958) within and beyond the region where it is developed.

The spread effect of tourism industry take the form of the demand for backward region's agricultural products, cultural materials and services; migration of unproductive population, unemployed and replaceable employed population; investment in the peripheral region by direct investment or capital transfer; direct transfer or spending of earned income by workers and the accessibility to urban utilities and services. The mechanism of the cumulative growth and the economic impacts that follow initial investments in an area, apart from creation of employment also include income generation resulting from successive rounds of subsequent investment in various sectors of the regional economy (Pred, 1966: Loyd and Dicken, 1977). Earlier studies of scholars had shown that the subsequent turn-around of expended income by workers in a region will eventually bring about regional economic growth and development within its zone of influence (Abiodun, 1982; Ajala and Olajuyin, 1996; Ajala, 1997). Thus, the focus of this paper is to examine the effect of direct employment of tourism industry in four sectors such as Hotel, Souvenir business, Tour guide and Water transport businesses and as well the income generating potential to the regional economy of Amhara Region, Ethiopia.

\section{Study Area}

Amhara National Regional State, with Bahir Dar as the regional capital, is one of the nine regions in Ethiopia; located in the North western part of the country. It has a total land area of $161,828.40$ squared kilometers, with a population of 17,266,383 as at 2005 (Amhara BFED, 2005). Amhara region is divided into eleven administrative zones; each is further divided into "Woreda" (administrative 
community). Amhara region is basically a rural region with 89 percent of its population in the rural areas while only 11 percent are urban dwellers. The region is quite homogeneous in terms of culture. The national regional language is Amharic but other major languages in the region include Awi, Oromo and Argoba.

Bahir Dar is located within the central plateau of Ethiopian highlands, sharing the shore of Lake Tana, the source of Blue Nile a major tributary of River Nile which is the longest river in Africa. It lies at an altitude 1830 metres above sea level, with an average temperature in the range of $12-18^{0}$ centigrade and rainfall between 400- 2000mm, usually from June to September (Figure 1).

Bahir Dar, has a population of 145,982 as at 2002, it is declared a special zone in Amhara region being the regional capital. It is the home of the Gojam tribe of Amhara, it has witnessed rapid urbanization and physical expansion in recent time due to rural-urban migration.

Lake Tana, is one of the largest inland water lake in Africa with the total area of 3600 $\mathrm{km}^{2}$, stretching 75 kilometres North and South ,60 kilometres East-West and lying at about 1830 metres above sea level and having 14 metres maximum depth (Amhara, 2005).

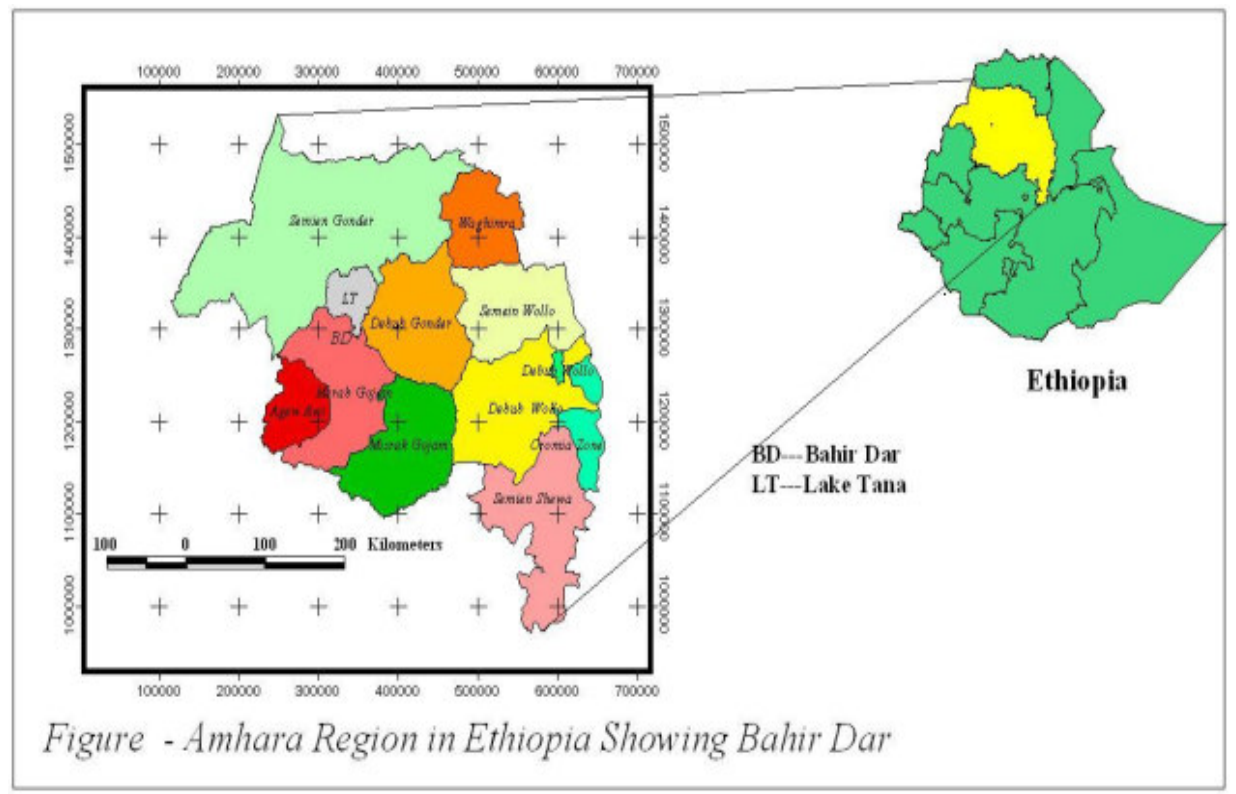

\section{Methodology}

Data were collected from both primary and secondary sources. The secondary data were sourced from the published and unpublished records of Bureau of Culture and Tourism in Amhara Region, Ethiopia.

Primary data were collected through:

I. Inventory field survey of Tourist facilities- hotels and souvenir shops on the street, apart from the main market
II. Four sets of questionnaires for Hotel managers, tourist guides, boat captains and tourists

The main field work for the research was carried out in Bahir Dar while other records were extracted from the secondary sources due to financial constraint on the part of the researcher. Using the designed questionnaires a total of 9 Hotels, 75 Tour guides, 58 Boat captains and 92 souvenir shops were covered in the field work. Data collected from both sources were analysed using simple statistical methods as frequencies and percentages. 


\section{Results and Discussion}

The section focused on the findings of the research, it is divided into subsections to pin point different aspects of the potentiality of tourism development within Amhara region.

\section{a) Tourist Attraction Locations in Amhara Region}

Amhara region is blessed more with abundance and diversify natural environment than other regions in Ethiopia. It has more of the tourist attraction locations within it boundary. The major tourist attraction locations have been grouped into four according to Bureau of culture and tourism in Amhara region (Tourism Commision, 2005) as follows :

1. Simen Mountain National Park is the most marvellous of Ethiopian landscapes lying mainly to the north east of Gondar Town. As one of the major Mountain massifs of East Africa, it has many summits that rise up to more than 4000 meters above sea level. Ras Dashen is the highest peak which is 4620 meters above sea level, the highest in Ethiopia and the fourth in Africa. Simen National Park is blessed with diverse fauna and flora apart from the marvellous mountain scenery, these include Ethiopian Red Fox called Simen Fox, Chilada Baboons, Wild goat (Walia Ibex); birds like Eagles, Vulture and several plant species.

2. Rock-Hewn Churches of Lalibela listed as one of the World's heritage by UNESCO. It has eleven ancient churches some of which dated back to between $6^{\text {th }}$ and $11^{\text {th }}$ century.

3. Fassil- Gebbi Castles of Gondar is another World's heritage site, $175 \mathrm{~km}$ from Bahir Dar..It has Old palaces of Emperors and Orthodox Churches where the ancient architectural designs and stone constructions are still preserved; built around $17^{\text {th }}$ and $18^{\text {th }}$ century represents Ethiopian civilization.
4. Bahir Dar, the capital city of Amhara regional state serve as the gateway to the main attraction location in the region with several tourist sites which include: Lake Tana, Islands and Peninsular Monasteries, Blue Nile falls, Wanzaye Hot spring, Orthodox churches , cultural activities, Souvenirs and artefacts of silver, brass and gold.

\section{b) Employments Generation Potential of Tourism Enterprises}

Direct employment is one of the potential of tourism enterprises in any location where it is developed. Tourism Enterprises are defined business units which provide direct services to tourist in a given tourist destination. This includes such services as hotel services, souvenir shops, tour guide, special transport services (such as boat, horse riding, cycling, cable cart etc.). In Amhara Region, four tourism enterprises were identified to provide direct employment opportunities in the region. These are Hotel services, local tour guiding, and boat riding on Lake Tana and souvenir shops. Apart from the record from Bureau of Culture and Tourism, The field work on these aspects was carried out mainly for Bahir Dar from which a projection can be made for the whole region.

Table 1 showed the number of hotels available in each of the four tourists' destinations in Amhara region. Hotel services played a major role in the tourism industry and are one major enterprise that employs a large number of people in the industry. In Amhara region there are about seventy hotels of different categories, out of which Bahir Dar has $33(47 \%)$ of the total. Going by the findings in Bahir Dar, where the actual number of hotel is more than double of the recorded; one can assume that the total number of available hotels irrespective of categories can be almost double or at least more than the available figure as at present if inventory were to be taken in other locations as well.

From the 33 Hotels identified in Bahir Dar, only 12 were of standard that received international tourist with good facilities. The remaining 21, provide services for domestic tourists. Out of the 12 standard ones, only nine 
accepted to release information about their services, operations and management. Thus employment generation potential from hotel enterprises was based on the figures released by these nine from which a projection was made for the 33 hotels recorded for Bahir Dar, this yielded 1584 direct employments in the hotels enterprises for Bahir Dar alone (Table 2).

Other direct employments are generated from tour guiding (75), boat captains (58) and souvenir shops (184) (see Tables 3 and 4). The Total Direct Employment generated by these four Tourism service i.e. Hotels, souvenir shops, tourist guides and Boat captains can be derived by this simple formular-

$\mathrm{TDE}_{(\mathrm{TD})}=\mathrm{f}\left(\mathrm{a} \mathrm{x} \mathrm{n}_{(\mathrm{H})}+\mathrm{bx} \mathrm{n}_{(\mathrm{Ss})}+\mathrm{Tg}+\mathrm{Bc}\right.$ $+\ldots . .+n)$

Where TDE $(\mathrm{TD})^{-}$is Total Direct Employment in Tourism Industry in a particular Tourists destination (TD)

a- is a measure of average number of employees per hotel

$\mathrm{n}_{(\mathrm{H})}$ - is Number of Hotel in the location under consideration

b-is a measure of average number of employees per souvenir shop

$\mathrm{n}_{(\mathrm{Ss})}$-is number of souvenir shops within the study area

$\mathrm{Tg}$ - number of Tour guides

Bc- number of Boat captains

$+\ldots . .+n$-allows for additional tourism services that generate direct employment in the industry which may be different from one location to the other.

Then, for Bahir Dar alone Tourism development is currently generating direct employment of about-1901 \{ i.e. $\mathrm{TDE}_{(\mathrm{TD})}=$ $(48 \mathrm{X} 33+2 \mathrm{X} 92+75+58)$ $=1584+184+75+58=1901\}$

The indirect employment from tourism development will be much more as it cut across several sector of the economy.

\section{c) Income Generation Potential}

Income generation potential of tourism enterprises is another mechanism through which tourism industry is impacting on regional economy where it is developed. This mechanism is a bit wide and complex as it cut across several sector of the economy through which income exchange hands in the process. However, the research focused on the direct income to employees in specific tourism services particularly, income generation to tour guide and boat captains. The record of the estimated regional income generation from international tourist was also used for further discussion. The income to hotel workers and souvenir shop and the expenditure pattern of tourists were not part of this discussion because it constitutes another dimension of the income multiplier effect of tourism enterprises in a given tourist destination.

Table 5 showed the pattern of income generation per week among the local tour guides in Bahir Dar. According to Table 5, 75 percent of tour guides in Bahir Dar were earning between 200-500 Birr per week. This is equivalent of between \$20 - \$50 US dollars, the exchange rate as at the time of field work was 9.20 birr to $\$ 1$ US dollar. The remaining 25 percent of tour guides were earning between 500-100 Birr or more. This is between \$50-\$100 US dollars per week.

On the other hand, the income generated to individual boat captains is more than that for the ordinary tour guides as their own service required some investment and training. 46 percent of the boat operators on Lake Tana were earning between 1000 -1500 birr an equivalent of \$100- \$160 US dollars per week, another 29 percent were earning between \$50-\$100 US dollars per week by conversion. Those who are earning above $\$ 160$-\$250 US dollars are boat owners. Their income per trip is however subject to the distance covered to -fro from the harbour (see Table 6)

This revealed that this aspect of tourism enterprises is very lucrative and it is attracting the interest of youth in the area. It also implies that the engagement of youth as tour guides at various tourists' destinations in 
the region and as boat captains for special transport on Lake Tana is yielding economic benefits not only for youth who constitutes the workers in these enterprises but also to the entire regional economy, apart from reducing the social problems associated with unemployment in the society.

\section{d) Tourist Flow and Regional income Generation in Amhara Region}

The viability of any enterprises depends more on the rate of patronage by consumers. Tourism industry and the associated enterprises are location specific and services oriented. The range of goods and services has influence on the threshold population required for the survival on any enterprises. Tourism as an international commodity has its range extend to the whole world where it draws its consumers and the consumers has to get to the tourist destinations to enjoy the pleasure of tourism. In Amhara region threshold population to sustain tourism enterprises is guaranteed as it an all year round business. Tourism enterprises in Amhara region draw its consumer both from within the country as domestic tourists and from different parts of the world as international tourists.

In 2004 alone Amhara region received a total 119, 044 domestic and 44,502 international tourists at various tourists' destinations in the region, while in 2005 the record was 51,089 domestic and 45,428 international tourists. The reduction of the domestic tourist for 2005 was due to nonavailability of data from Lalibela location for that period (see Tables 7 and 8). Looking at the trend from the two tables it indicated that the tourists flow is ever increasing from year to year, thus tourism enterprises would ever have the required threshold population to sustain its growth which is yet to reach its maturity stage in the region.

From Table 8, the estimated total income generated through international tourists was 40,185,732 and 42,174,169 Ethiopian birr for 2004 and 2005 respectively. This regional income from international tourists is quite enormous; this is just income to various tourism enterprises in the region and from flight ticket and entry visa fee paid to the nation and the airlines. This has the capacity of generating a lot of multiplier effects in various sectors of the regional and national economy of Ethiopia and even across international boundaries through importation of construction materials, household commodities and equipments.

\section{Conclusion}

The employment and income potentiality of four tourism enterprises was examined in this paper. The findings revealed that within Bahir Dar alone the four enterprises currently generated more than 1900 direct job opportunities at various categories with the hotel enterprise generating the highest employments. By projection tourism enterprises in the whole of Amhara region would be generating close to 10,000 direct employment opportunities in the four tourist destinations. The indirect employment could be double this figure as it cut across several sector of the regional economy.

The income generating potential is also revealing in that direct income are generated for both Entrepreneurs and the Labour Force in the Tourism Industry, apart from Taxes paid to Government by both the tourists and Investors in the tourism sector.

Indirect income is generated for other stakeholders through indirect employment and supplies of materials to the hotels and restaurants. The spending by tourists and the workers has multiplier effects within and beyond the regional economy of Amhara, to the country and across international boundaries, through the import of materials for constructions, equipments etc. The Study has revealed a dimension of the economic impact of tourism development using Amhara region as an example.

\section{Recommendations}

The observation within the region indicates that Tourism enterprises development potential is yet to reach its limit, thus, investors and government can still collaborate in many ways to expand this potential beyond its present situation. In this case the following recommendations are put forward. 
- The stakeholders in the industry can develop strategies of expanding the potential employment and income generation of the industry in the region.

- The Federal and Regional governments should collaborate on packaging and promotion of tourism attractions destinations in the region at international forum.

- Regulatory agencies and investors should work together in area of standardization of services and products as well as pricing of some services to the benefit of the economy.

\section{References}

Abiodun,J.O (1982) "the spatial impact of growth firms case studies from ondo state . southwestern , Nigeria" Indian Journal of Regional science, vol.xiv. No.1

Ajala . O A and olajuyin . LO (1996) "Regional impact of the international Breweries plc,Ilesa an analysis of input acquisition, product distribution and labour force Ife social science review vol. 13, nos .1\&2 .pp63-68 .

Ajala O. A. (1997) Employee's Income Multiplier Effects of International Breweries Plc.Ilesa, Nigeria Ife Research Publication in Geography vol.6 pp170-176

Ajala O.A. (2007) Tourism Development as a strategy in Regional Planning. African Research Review Vol.1.no3 pp77-92

Amhara Region (2005) Development Indicators of Amhara Region 2005, Amhara Regional State Bureau of Finance and Economic Development.

Amhara Region (2005) Ethiopia-Amhara National Regional State Tourist Attractions, Amhara National Regional State Tourism Commission.

Amhara Region (2006) Ethiopia-Guide to Top Tourists Destinations of Amhara National Regional State. Bureau of Culture and Tourism.

Boudeville J.R. (1966) Problems of Regional Economic Planning, Edinburgh University Press, Edinburgh.
- Incentives and concessions can be packaged by both Federal and Regional governments to encourage both local and international investors to increase the growth in the industry.

- $\quad$ Research and training is still required in the sector for further development in the sector if its full potential to regional development is to be realised.

These recommendations are believed to be necessary in the course of shaping the future of tourism enterprises not only in Amhara Region but the country at large.

Darwent. D.F. (1975) "Growth poles and centres" Regional Policy Cambridge The MIT Press, vol. 1. No .1.

Erickson .RA .(1974 ) "The Regional Impact of Growth firms the case of Boeing , 19631968" Land Economics vol. 50 pp.122-132 .

Hirschmann, A.O.(1958) .The strategy of economic development. Yale university press, Lloyd P.E.and Dicken P. (1977), Location in space a theoretical approach to Economic Geography. Harper and Row ,London .

Myrdal G. (1957) Economic theory in under developed regions Gerald Duckwoeth,

London.

Perroux , F.(1950) "Economic space theory and Application". Quarterly Journal of Economics vol.64, pp. 90-97 .

Pred, A. (1966) The spatial Dynamics of U.S. Urban -Industrial Growth 1800- 1914. Cambridge M.I.T press .

NTDC (2002) Nigeria: Beauty in Diversity a handbook on Nigeria Tourism. Nigeria Tourism

Development Corporation, Abuja Nigeria

Puczko L.R. (1998) "Rural Tourism and Sustainable Development" International conference on the Rural Tourism management, Scotland.

Renard Y. (2001) “ Practical Strategies for Pro-Poor Tourism: A case study of 
the St. Lucia Heritage Tourism Programme" PPT Working Paper No. 7 http://www.propoortourism.org.uk

Tanimowo N.B. (2002) Tourism for Rural Development in Nigeria--. in Ibitoye O.A.(edit.) Rural Environment and sustainable Development in Nigeria . pp 62-64

World Bank (1975) Rural Development Sectoral Policy, Policy paper on rural enterprise and non-farm employment, World Bank, Washington D.C.

WTO (2001) World Tourism Organization Annual Report,World Tourism Organization, Barcelona, Spain
WTTO \& IHRA (1999) “ Tourism and sustainable Development: The Global Importance of Tourism" Background Paper 1 Prepared by World Travel and Tourism Organization and International Hotel and Restaurant Association Commission on Sustainable Development.

WTTC, WTO, \& EC (1997) “ Agenda 21 for the travel and Tourism Industry: Towards Environmentally Sustainable Development" Presented at the 1997 United Nations General Assembly.

World Travel and Tourism Council, London, World Tourism Organization, Madrid and Earth Council San Jose.

Table 1 Hotel by Major Tourists Attraction Destinations in Amhara Region

\begin{tabular}{|l|l|}
\hline Tourists Attraction Destination & Number of Hotels \\
\hline Bahir Dar & $16(33)^{*}$ \\
\hline Gondar & 22 \\
\hline Lalibela & 12 \\
\hline Debark (Simen Mountain National Park) & 3 \\
\hline Total & $53 \quad(70)^{*}$ \\
\hline $\begin{array}{l}\text { Source- Record of Bureau of Culture and Tourism } \\
\text { *-Fieldwork } 2007\end{array}$
\end{tabular}

Table 2 -Some Hotels by type of Rooms and Total Number of Employees in Bahir Dar

\begin{tabular}{|l|l|l|l|l|l|}
\hline Names of Hotels & $\begin{array}{l}\text { Single } \\
\text { Rooms }\end{array}$ & $\begin{array}{l}\text { Double } \\
\text { Rooms }\end{array}$ & Suite & $\begin{array}{l}\text { Total Number of } \\
\text { Available Rooms }\end{array}$ & $\begin{array}{l}\text { Total } \\
\text { Number of } \\
\text { Employees }\end{array}$ \\
\hline Azewa & 21 & 02 & 05 & 28 & 37 \\
\hline Bahir Dar & 15 & 08 & 00 & 23 & 24 \\
\hline Blue Nile & 39 & 06 & 10 & 55 & 58 \\
\hline Dib Ambessa & 34 & 23 & 02 & 59 & 73 \\
\hline Enkutatash & 05 & 03 & 00 & 08 & 13 \\
\hline Ethio-star & 23 & 42 & 02 & 67 & 77 \\
\hline Ghion & 10 & 18 & 02 & 30 & 50 \\
\hline Rohama & 23 & 01 & 03 & 27 & 47 \\
\hline Summer land & 18 & 10 & 12 & 40 & 55 \\
\hline Total & & & & 337 & 434 \\
\hline & & & & & Average 48 \\
\hline
\end{tabular}

For 33 hotels in Bahir Dar Total employees will be 33 X 48=1584. Source- Fieldwork 2007 
Table 3 Tourist Guide by Major Tourists Attraction Locations

\begin{tabular}{|l|l|}
\hline Tourists Attraction Destination & Number of Tour Guides \\
\hline Bahir Dar & $36(75)^{*}$ \\
\hline Gondar & 25 \\
\hline Lalibela & 69 \\
\hline Debark (Simen Mountain National Park) & 21 \\
\hline Tiss Abay Water Fall & 15 \\
\hline Lake Tana Islands Monasteries ( zegie) & 16 \\
\hline Total & $182(221)^{*}$ \\
\hline
\end{tabular}

Source- Record of Bureau of Culture and Tourism *-Fieldwork 2007

Table 4- Number of Employees in Souvenir Shops and Boat Captains

\begin{tabular}{|l|l|}
\hline Tourist Service & Number of Employees \\
\hline Souvenir Shops & $(92 \times 2)=184 *$ \\
\hline Boat Captains & 58 \\
\hline *-Fieldwork 2007
\end{tabular}

Table 5 Tourist Guide Income per Week

\begin{tabular}{|l|l|l|}
\hline Income Group (Birr) & Frequency & Percentage \\
\hline $200-250$ & 22 & 29.3 \\
\hline $251-500$ & 35 & 46.6 \\
\hline $501-1000$ & 08 & 10.8 \\
\hline$>1000$ & 10 & 13.3 \\
\hline Total & 75 & 100 \\
\hline
\end{tabular}

*-Fieldwork 2007 \$1 US Dollar was 9.20 birr as at November2007

Table 6 Boat Captain Income per Week

\begin{tabular}{|l|l|l|}
\hline Income Group (Birr) & Frequency & Percentage \\
\hline $500-1000$ & 17 & 29.3 \\
\hline $1001-1500$ & 21 & 46.6 \\
\hline $1501-2000$ & 12 & 10.8 \\
\hline$>2000$ & 05 & 13.3 \\
\hline Total & 58 & 100 \\
\hline
\end{tabular}

*-Fieldwork 2007 \$1 US Dollar was 9.20 birr as at November2007

Table 7-Domestic Tourist Flow 2004-2005

\begin{tabular}{|l|l|l|}
\hline Locations & \multicolumn{2}{|c|}{ Number of Tourists } \\
\hline & $\mathbf{2 0 0 4}$ & $\mathbf{2 0 0 5}$ \\
\hline Lalibela & 71,361 & NA \\
\hline Bahir Dar & 14,743 & 34,140 \\
\hline Gondar & 32,516 & 16,442 \\
\hline Debark* & 424 & 507 \\
\hline Total & 119,044 & 51,089 \\
\hline
\end{tabular}

Source- Bureau of Culture and Tourism Record 2007

*Simen National Park

Table 8-International Tourist Flow and Estimated Revenue 2004-2005

\begin{tabular}{|l|l|l|l|l|}
\hline Locations & \multicolumn{2}{|l|}{ Number of Tourists } & \multicolumn{2}{l|}{ Estimated Revenue (Birr) } \\
\hline & $\mathbf{2 0 0 4}$ & $\mathbf{2 0 0 5}$ & $\mathbf{2 0 0 4}$ & $\mathbf{2 0 0 5}$ \\
\hline Lalibela & 18,320 & 18,170 & $17,880,320$ & $19,550,920$ \\
\hline Bahir Dar & 9,243 & 12,969 & $9,700,167$ & $10,317,729$ \\
\hline Gondar & 12,289 & 8,777 & $9,764,531$ & $9,218,083$ \\
\hline Debark* & 4,650 & 5,512 & $2,840,714$ & $3,087,437$ \\
\hline Total & 44,502 & 45,428 & $40,185,732$ & $42,174,169$ \\
\hline
\end{tabular}

Source- Bureau of Culture and Tourism Record $2007 *$ Simen National Park 